detailed treatment than can here be devoted to them ; and in hilly, broken country, such as the Konkan (a part of the Bombay province), the conditions of water-supply being so obviously varied, it is not surprising to find that there is practically no cholera season there. The disease is here as likely to come at any one season as at any other. I think enough has been said to illustrate the fact that for the prevalence of free epidemic cholera a certain moderate amount and high level are needed in water-supplies, and that this quantity, being attained or approached at different periods of the year, according to locality and rainfall, is the main cause of seasonal variation of epidemics throughout India. The suggestion that the depressing influence of very heavy rain on the manifestation of cholera is simply the result of overdilution is further borne out by the following observation. It is that, generally speaking, heavy rain is capable of completely blotting out epidemic prevalence. It can only temporarily depress it. This is true of the very heavy rain of Assam and Bengal, and of the comparatively heavy northeast rains of the Carnatic. The only instance of a stronger influence than this that I have been able to find lies in the variations above normal of the light south-west monsoon in the Carnatic. This requires a little attention. The explanation probably lies in the fact that the period of the southwest monsoon is here to be regarded as the breeding season of epidemics, ${ }^{17}$ and a slight excess of rain at this period is fatal; whereas if the showers remain light the epidemic becomes established, and later heary rain can only temporarily check it. Some almost of the highest mortalities from cholera here have immediately followed excessive autumn rains.

From all this it is seen how the disease comes to be perennial in countries such as the old "endemic area." It is simply that the water-supply there is always at least sufficient ; on the other hand, scarcity (which means low level) of water, seen in Berar and in the Panjab, is the condition associated with complete seasonal disappearance of the disease. Of this there are at least two explanations. An obvious one is that the depth of water below the surface renders wells less liable to pollution, bat it is obviously also incomplete. I believe that the more influential factor is purely a matter of temperature. The stimulating influence of high temperatures on cholera is too well known to need support here. The depth of well water in these districts after the rains are over probably places it beyond the influence of a winter sun's rays; and, though the cholera organism may survive in these wells, its vitality is lowered and it is unable to multiply rapidly. But it must be acknowledged that even in Berar usually a few scattered pools persist in the river beds throughout the year; and there may be small outbreaks of the disease traceable to their use. Cholera has even on rare occasions, when the temperature has been persistently higher than normal, been mildly epidemic in the hot weather here. Probably on these occasions the sun's rays to some degree penetrated even to the deeper water levels. In the winter months this has never happened; the sun is not powerful enough. Hence there have been nothing beyond isolated cases and the smallest outbreaks. The influence of recession of water level below the surface in these countries of scanty supply is seen in the fact that they are the only provinces quite exempt from outbreaks and epidemics for a portion of the year; and the cold weather temperature of Berar is not lower than that of Lower Bengal or Assam. It will perhaps be as well to give another illustration of the effect of recession of water level and of atmospheric temperature on cholera intensity. In Lower Bengal cholera is at a minimum during the rains because the organism is sparsely scattered through the flooded water supplies. It rapidly rises, with a falling water level, till December. The cholera material is now more concentrated, and the water level is still high enough to be within the influence of the sun's rays; but after this the well water still recedes, and, I presu me, does not get quite sufficiently heated. The mortality from cholera hence drops somewhat till February. The hot weather then begins, and the water level remains practically without further change. The consequence is that the organism revives, and the mortality rises to the maximum of the year in April. It is noteworthy that the rain of May at once depresses the cholera rate, though it produces no drop in temperature nor affects the level of wellwater. It must act by diluting the poison in the water of tanks.

The character of the increase of cholera in the greater part of India shows that the cholera organism may lie dormant in water-supplies, only exhibiting pathogenic properties (possibly owing simply to rapid multiplication) when the conditions of temperature, rainfall, pressure, \&c., are favourable. I have recently published papers ${ }^{18}$ showing so close a relation between the weather and the disease in Bombay, Madras, and-I think-Berar, that cholera must be widely endemic in these provinces : yet not so typically endemic as in Lower Bengal and the Assam valleys, tor the influence of human intercourse is more visible in outbreaks in the former provinces, though it is lost in the epidemic history of the provinces, each being considered as a whole. Probably the proportion of water-supplies in which the organism can find a permanent home is mach smaller than in the Gangetic delta ; yct they must be widely spread. On the other hand, in the Punjab and Sind cholera is almost on foreign soil. Judging from the results of the Hurdwar fair epidemics, human agencies here appear to have a larger influence on epidemic prevalence than have weather conditions. Endemicity and spread by infection stand at the two ends of a scale.

Confusion seems to have arisen between the terms "endemic" and "perennial," probably because both are characteristic of cholera in the delta of the Ganges. The fact that cholera is perennial in a district simply indicates the stagnation of subsoil water and its nearness to the surface. In some of the low-lying districts of Madras and Bombay the disease continues throughout the year; but there come breaks in its prevalence of one or more years. It is not. more endemic here than in districts of definite seasonal limitation. The disappearance of the disease on black cotton soil in the winter in no way implies a need of reinfection from without to start its next seasonal manifestation.

In conclusion, I have done little more in this paper than collect and connect a few well-known facts. The inferences drawn are some of them speculative. Though they cover all the facts as they are at present known to me, much more exact eviderce is needed before they can be regarded as other than mere suggestions, and the peculiarities of Indian water-supply must be taken into account. Generally speaking, there are two distinct sources of supply: (1) wells, usually shallow wells; and (2) surface water, including "tanks" or reservoirs, pools, and running streams; and the $t$ wo classes are generally combined in the one district. The result may be somewhat confusing. Shrinkage of tank supplies may mean concentration of specific poison in them, and hence increase of cholera. Carried a stage further, it may enforce a freer use of well water, possibly now pure, though being at a considerable depth. On the other hand, the influence of a moderately high level of well water may be counteracted by flooding of tanks and river beds.

Table showing Decrease in Cholera Mortality and Rainfall nestward from Lower Bengal.

\begin{tabular}{|c|c|c|}
\hline $\begin{array}{l}\text { District or } \\
\text { Collectorate. }\end{array}$ & $\begin{array}{l}\text { Average annual rain- } \\
\text { fall in inches at the } \\
\text { chief station of the } \\
\text { district. }\end{array}$ & $\begin{array}{l}\text { Cholera mortality, } \\
\text { average annual ratio } \\
\text { per 1cto of civil popu- } \\
\text { lation of the district. }\end{array}$ \\
\hline 24 Pergunnahs... ... & $61 \cdot 50$ & $2 \cdot 37$ \\
\hline $\begin{array}{lllll}\text { Patna } & \ldots & \ldots & \ldots & \ldots\end{array}$ & $43 \cdot 12$ & 1.57 \\
\hline Allahahad $\ldots \quad \ldots \quad \ldots$ & $38 \cdot 51$ & $1 \cdot 19$ \\
\hline $\begin{array}{llll}\text { Cawnpore } & \ldots & \ldots & \ldots\end{array}$ & $31 \cdot 29$ & 0.65 \\
\hline $\begin{array}{lllll}\operatorname{Dell} i \mathrm{i} & \ldots & \ldots & \ldots & \ldots\end{array}$ & $28 \cdot 00$ & 0.37 \\
\hline $\begin{array}{llll}\text { Mooltan } & \ldots & \ldots & \ldots\end{array}$ & $6 \cdot 90$ & $0 \cdot 18$ \\
\hline
\end{tabular}

Rajkote, Kattywar, India.

\section{THE TREATMENT OF PROLAPSUS RECTI BY GALVANISM.}

By R. B. MITCHELL, M.D. EdIN.,

MEDICAI STPERINTEXDENT OF MIDLOTHIAY AND PEEDLTS DISTRICT LENATIC ASYLEM.

THE treatment of prolapsus recti by galvanism, though not mentioned in any works on surgery that $I$ have seen, would still appear to be of some value; and the fact that $I$ have 
lately employed this means successfully in three very bad cases induces me to put on record the following brief notes on the subject as likely to be of some interest.

CASE 1.-A man about fifty-five years of age, suffering from melancholia with homicidal tendencies. Prolapsras recti occurred in March, 1892, and recurred frequently till the following July. Galvanism was applied soon after the bowel was replaced on the first occasion, and about once a week thereafter. After four montbs' treatment the bowel ceased to protrude, and between July, 1892, and May 13th, 1893, at which latter date the patient was sent to Ireland, no relapse occurred. He thus remained well for a period of at least ten months, and the tone of the sphincter seemed quite restored at the date of bis leaving the asylum.

CASE 2-A female chronic maniac fifty years of age. Prolapsus recti occurred in December, 1889. She concealed her condition at first, and when it was detected the protruded portion of gut was as large as a cricket ball and intensely congested and bleeding. The hernia could not be reduced till the patient was put thoroughly under chloroform. After the bowel was replaced the sphincter was so relaxed that five fingers could be easily inserted into it nearly as far as the proximal ends of the third phalanges. Galvanism was soon applied, but the bowel came down again frequently - in fact, almost every time that micturition was performed and every time that the bowels were evacuated. The cure was doubtless delayed by the obstinate conduct of the patient in concealing her condition every time a prolapse occurred; but after six months of galvanic treatment the bowel ceased to protrude, and the patient has now remained quite free from any return of the disorder for over three years and a half.

CASE 3.-A man thirty-two years of age. This patient was suffering from general paralysis of the insane and great impairment of the motor and ccördinating powers of the lower limbs. Obstinate constipation was a feature of the case. Prolapsus recti first occurred in December, 1892. Galvanism was applied frequently for six months without much apparent benefit; but after eight months' treatment the bowel seemed to have lost its tendency to come down, and now for four months the patient has been quite well in this respect. The state of the spinal cord constituted a very unfavourable element in the prognosis in this case.

Remarks.-Galvanism seems to have been saccessfully employed over thirty years ago in three cases of prolapsus ani, ${ }^{1}$ this is the only reference to the subject that I can find. In my cases an ordinary Smee's battery was employed. One pole was applied to the sphincter anj, the other pole to the spinous processes of the sacral and lumbar vertebræ, and the current made to pass for five minntes. This was repeated once or twice a week, whenever the bowel had to be replaced. The strength of the current was slight at first and gradually increased to nearly full strength. One disadvantage of this method of treatment is the long time required to effect a cure, but it must be admitted that more frequent applications might have been followed by more rapidly successful results. The classes of cases most suitable to treat in the way above noted are probably children and other restless patients, especially lunatics, who generally cannot be trusted to leave alone the wounds following an operation about the anus, and who are generally with the greatest difficulty prevented from tearing off dressings and bandages, or any retentive apparatus.

Rosslyn Castle, N.B.

\section{CIRCUMSCRIBED ATROPHY OF THE HAIR AND SKIN OF THE SCALP.}

\author{
BY TOM ROBINSON, M.D. ST. AND.
}

IT is not within the range of these few remarks to allude to the common form of bald patches which are met with in the hairy parts of the body. These are undoubtedly due to the invasion of the skin by a micro-organism, and they are known by the generic name of alopecia areata. But I am desirous to call attention to a groug of cases which, so far as I know, have not hitherto been described, and which are distinguished by the following attributes:-1. The atrophic areæ are confined to the scalp. 2. The areæ are

1 Medical and Chirurgical Review, vol. i., p. 106, 1859. absolutely bald. 3. The areæ are depressed like ordinary scars. 4. The hair never returns. The following case is an example of the condition.

A woman thirty-nine years of age, who has always had a fair share of health and who is the mother of six children. came to me in 1893 because "her hair was coming out." There was nothing unusual in her skin or epidermic strue tures, but on examination she had a cluster of bald patches on her scalp, which were practically confined to the parietal regions. They varied in size from a split pea to a shilling; some had joined at their circumference. I could not obtain a history of any inherited tendency towards the condition, and it may be taken as a fact that she had not been syphilised. Neither had she at any time been the subject of severe headaches or had any injury. The scars (for such they literally were) resembled those one sees when lupus erythematosus attacks the scalp or when a scald or a burn has been inflicted. I have looked carefully through my notes taken during the last ten years, and, altbough $I$ find that thirteen such cases have consulted me, in every instance the patient has been a woman. I have naturally asked myself the question, "Why do these patches occur?" and I confess to an inability to find a satisfactory reply. The medical man might shelter himself behind $a$ theory of local anæmia, which in the first degree would produce a diminished growth of hair, and if continued would lead to atrophy or even to local death, but no one would accept such a hypothesis. Cases of loss of hair which have been either a sequel or a symptom connected with profound disturbance of the nervous system are on record. Cooper Todd described the case of a man who fell from a waggon and sustained injuries which caused hemiplegia and loss of consciousness, and who one day on going to shave him. self could not find any beard. Fischer, who had great experience in military surgery, noticed after ganshot wounds that the limb corresponding to the wound received (if that wound had interfered with the nervous integrity of the part) became bald. Virchow describes a circumscribed atrophy which has been observed in one-half of the face, but at times in other parts of the body. On careful examination of the whole cutaneous area of an old man evidence of cutaneous wasting will usually be found occurring locally and generaliy, the skin being wanting in lustre, and in scme old and thin men I have seen the epidermis of the face and shins stretched over the bones like a piece of hog's bladder. Wilson called the condition derma toxerasia. Celsus, in his chapter de areis, describes a form of baldness which probably refers to the case now under discassion. It is what he calls the worst form-namely, that which destroys the fat and renders the surface totally smooth-but he confuses it obviously with alopecia areata One may without any unfair straining of theory easily under stand that the injurious and positively cruel way in which women produce the cuiling of the hair will account for an injury to the scalp. Curling pins, curling irons, and curling papers form an essential part of the toilet armoury of almost every woman, and this torturing of the hair drags on the roots, and by so doing starts the inflammation which may be the forerunner of this atrophy. The scalp being so dull of sensation will enable the victim to bear a good deal of tension without much suffering. Again, the number of hairpins used in dressing the head may damage the scalp.

Prince's-street, Cavendish-square, $\mathrm{w}$.

\section{RECOVERY FROM OVARIOTOMY: FIVE WEEKS SUBSEQUENTLY DEATH FROM CANCER OF THE PANCREAS AND DUODENUM.}

BY JOHN D. MALCOLM, M.D, C.M., F.R.C.S. EDIX SURGEON TO THE SAMARITAN FREE HOSPITAL.

A congenital deat-mute, single, forty-nine years of age consulted me on Feb. 23rd, 1892, on account of an enlarge. ment of the abdomen, which had been increasing for about five years, and yellowness of the skin, which had existed for three months. Emaciation had taken place, but not to any great extent until the last four or five months, during which time it had been very rapid, and the abdominal swelling had also increased more quickly. There had beer 